\title{
A Game Analysis of Trade Dumping and Antidumping
}

\author{
Huachun Zhao', Jeffrey Yi-Lin Forrest ${ }^{2}$, Benjamas Jirasakuldech ${ }^{2}$ \\ ${ }^{1}$ School of Economics and Finance, Jiangxi Normal University, Nanchang, China \\ ${ }^{2}$ School of Business, Slippery Rock University, Slippery Rock, PA, USA \\ Email: huaczhao@163.com, Jeffrey.for rest@sru.edu, b.jirasakuldech@sru.edu
}

How to cite this paper: Zhao, H.C., Forrest, J.Y.-L. and Jirasakuldech, B. (2018) A Game Analysis of Trade Dumping and Antidumping. Theoretical Economics Letters, 8, 2860-2881.

https://doi.org/10.4236/tel.2018.814179

Received: April 28, 2018

Accepted: October 16, 2018

Published: October 19, 2018

Copyright () 2018 by authors and Scientific Research Publishing Inc. This work is licensed under the Creative Commons Attribution International License (CC BY 4.0).

http://creativecommons.org/licenses/by/4.0/

(c) (i) Open Access

\begin{abstract}
This paper develops game theoretical models to study the interactive, competitive plays and relevant decision making regarding the dumping and antidumping actions between an importing nation and an exporting nation. The latter considers potentially dumping its product in the domestic market of the former, while the former attempts to protect its market and its domestic firms from exiting the market by implementing necessary trading strategies. Understanding how to deal with potential intruders, when to take actions, and what appropriate actions to take under different sets of conditions is very crucial both theoretically and practically, because countermeasures may or may not be effective depending on what conditions one is constrained with. The theoretical framework, established in this paper, will provide a better understanding of anti-dumping policies and their implications for regulators, policy makers, managers, and academicians, while the results developed herein can be readily employed in real-life scenarios, making this work practically useful for understanding how international trade conflicts could be handled effectively.
\end{abstract}

\section{Keywords}

China-U.S. Trade, Domestic Consumer, Nash Equilibrium, World Market

\section{Introduction}

According to David Ricardo [1], the development of international trade further promotes the deepening division of international labor. Due to the comparative advantage and the differences in the costs of producing the same products in different countries, each country manufactures the products that cost the least when compared to the production costs of other countries. Through interna- 
tional trade, this country acquires lower priced necessities of life from foreign countries. Such division of labor helps to lower wages, raise the profit margins of products, and create conditions for capital accumulation, which is conducive to the development of capitalist production.

The dramatic increase in the development of globalization has further amplified the scale of international flows of goods and services. In international trade, each country is both an exporter and an importer with mere differences in the magnitude of trade. It is often undeniable that in the current world, no country can independently develop its domestic economy without being involved in some kind of trade with other countries. As a result of the constantly increasing scale of international flows of goods and services, the problem of trade surplus and deficit becomes eminent, causing frequent occurrence of international trade frictions. As a consequence, the operational problem related to balancing trades has attracted more and more attentions of various national governments and become a hot research topic in the world of trade liberalization [2] [3] [4]. In recent years, there has been a dramatic increase in the number of industrial countries that face the problem of balancing trade. In particular, issues of multilateral trade negotiations between the United States, the largest economy of the world, and China, the second largest economy, are becoming more pronounced than ever.

Within the wide-ranging topic of international trade, the phenomenon of dumping and antidumping has been carefully investigated since more than a century ago, see, for example, [5]-[10]. Yet, as of the present day, dumping and antidumping are still some of the most poorly understood and contentious issues in the study of trade policies [11] with antidumping mechanisms most often used for protectionist purposes and for harassing trade partners. Filling this gap, this paper contributes significantly to the current literature of dumping and antidumping by taking a neutral stand between exporting and importing nations through using game theory in order to discover how exporters and importers actually interact with each other. We analyze the competition between one importing nation and one exporting nation within the context of the world economy. Established in this paper include very specific conditions for when antidumping measures would work, when they would only work partially, and when they would not work at all. Correspondingly, we further specify conditions for when dumping schemes would work effectively, partially or not at all. As a test of our established theoretical results, this paper investigates the present China-U.S. trade relationship critically and specify what our theory developed here actually implies for the policy decision makers of these two countries.

The rest of this paper is organized as follows. Section 2 provides a review of the relevant literature. Section 3 introduces the basic conceptual framework of the game played by two trading partners, an exporter and an importer. Then Nash equilibria are found for various scenarios: pure strategies, mixed strategies, and exporting and dumping in the world market. Section 4 includes the con- 
sumers of the importing nation as the third player in the game for the case that the exporting nation's revenue from dumping in the world market except that of the particular importing nation is less than its cost of production and dumping in the entire world market, while its total revenue is greater than the cost. Section 5 analyzes the costs and benefits of the trading partners for the scenario considered in Section 4. Section 6 uses the trading relationship of China and U.S. as a specific case and examine how our general theoretical results actually play out in the modern world of international economics. Section 7 concludes the presentation of this research.

\section{Literature Review}

The problem of how strategies of dumping and antidumping actually work in real life has been seriously looked at since more than a century ago [5]-[10]. However, as of this writing, the phenomena of dumping and antidumping are still some of the most poorly understood and contentious issues of business in general and trade policies in particular [11], while mechanisms of antidumping have been often employed for protectionist purposes and for harassing trade partners.

As the world becomes much more economically globalized along with a globally uneven distribution of resources [12], it is imperative for each nation to understand how to deal with dumping problems and how to implement different antidumping mechanisms effectively. For example, Dinlersoz and Dogan [13] consider the comparative effects of tariffs and antidumping duties, two important tools used to protect local industries from foreign competition while generating revenue. These authors study the effects of anti-dumping systems on prices, profits, government revenue, industry protection, and social welfare in a two-country framework and establish conditions under which one tool dominates the other for a given criterion. Kao and Peng [2] examine how price undertaking policies affect firms' product investments by showing that the dumping margin declines when the products become more differentiated. By using an intra-industry trade model they establish that under bilateral anti-dumping actions, the aggregate product $\mathrm{R} \& \mathrm{D}$ investment either increases or decreases, depending on the tolerable dumping margin set by the governments. However, if only one government implements anti-dumping actions, the aggregate product $\mathrm{R} \& \mathrm{D}$ investment will definitely decline and the products will become less differentiated.

By employing a monopolistic competition model with market segmentation and international price discrimination, Hansen et al. [14] empirically analyzes whether or not there is an inverse relationship between the elasticity of substitution and final ad valorem anti-dumping duties across products and provide evidence to support a negative relationship between the two variables. In terms of the impact of anti-dumping rules on firms' production decisions as to how much and where to produce, Haaland and Ian Wooton [15] find that anti-dumping 
measures may have unforeseen effects if they induce direct foreign investment and increase domestic competition. These authors then focus their attention on industrial location choices and strategies of national governments that attempt to advance the welfare of their citizens through anti-dumping legislation.

To understand why nations have increasingly applied antidumping measures, Moraga-González and Viaene [16] build a theoretical model of vertical intra-industry trade to investigate the strategic incentives for exporting firms to undertake dumping schemes. They find that dumping by both low-quality firms and high quality firms could occur depending on the circumstances involved. Instead of examining the strategic considerations of domestic firms seeking antidumping protection, Chen et al. [17] take the perspective of foreign competitors and investigate the conditions that influence foreign competitors' decision to either conduct or abstain from an antidumping rebuttal. Their results show that the potential value created from an antidumping rebuttal and the target product's stage within the product life cycle jointly influence the foreign competitors' reputation for toughness, which in turn determines whether or not foreign competitors pursue an antidumping rebuttal.

As antidumping has evolved as the most popular choice of strategy for trading nations in the recent decades, antidumping measures invoke a threat to exporters and thereby alter their strategic behaviors. In response to this form of antidumping mechanism, Bagchi et al. [18] describe the phenomenon of dumping by using a price-leadership model and compute the optimal level of antidumping duty that could offset the effect of dumping. By employing a sequential game, these scholars show that the credible threat of an antidumping duty restricts dumping, which ultimately leads to a win-win situation for both foreign and domestic firms.

So, in comparison this paper contributes to the literature on different fronts. First, it takes a neutral stand to realistically look at how a nation that dumps its products and another nation which imports the dumped products interact with each other in their effort to maximize their individual wellbeing. Second, instead of taking another empirical approach, this paper analyzes the competition between these two nations by developing game-theoretical models so that derived conclusions can be more reliable and applicable in practice than those developed on data mining. Third, by involving consumers from the importing nation, this paper also establishes models that deal with the situation of dumping in the world market. Fourth, this paper devotes an entire section to look at how the conclusions established herein can be employed to study the present China-U.S. trade relationship and what this work actually implies for the relevant policy decision makers.

\section{Dumping and Antidumping: A Two-Player Competition}

According to Article 2.1 of WTO [19] Anti-dumping Agreement, dumping is a situation where product is introduced into another country at a price lower than 
the price of comparable product that would have been sold in the domestic country. In this section, we consider two trading partner nations, one of which is the exporter while the other is the importer. For the sake of convenience of communication, let us assume that each of these nations produces one kind of product, both of which are horizontally differentiable but are considered as substitute of each other. That is, the substitution of the products is therefore inelastic [14]. Let the trading revenue of the exporting nation generated from dumping its product in the importing nation be $S_{\text {export }}$ and the revenue of the importing nation generated from its domestic market when the exporting nation does not dump its product be $S_{\text {import }}$, satisfying that when $S_{\text {export }}=0, S_{\text {import }}$ reaches its maximum. In other words, the revenue $S_{\text {export }}$ of the exporter from the importing nation through dumping its product is really a portion of the expected maximum revenue $S_{\text {import }}$ of the importing nation. As a result, we have naturally set up the condition $S_{\text {export }} \leq S_{\text {import }}$. If the importing nation takes counter measures, such as trade investigations, trade remedies, implementing trade retaliations of any mechanism against the exporting nation, against dumping [15], the cost incurred is assumed to be $C$. Let $R_{0}$ be the costs of the exporting nation, including risk and opportunity costs, for designing and producing the product for export when the importing nation does not take any defensive measures against dumping, whereas $R_{1}$ represents the costs when the importing nation imposes countermeasure(s) against dumping.

\subsection{Nash Equilibrium of Trade}

In this subsection, we analyze the theoretical game situation under two scenarios: 1) $S_{\text {export }} \leq R_{0}$ and 2) $S_{\text {export }}>R_{0}$.

If $S_{\text {export }} \leq R_{0}$, then the exporting nation would not dump its product into the importing nation. It is because the total revenue expected from dumping the product is no more than the sum of the cost of producing the product and the risk and opportunity cost even when the importing nation does not take any counter measure. In such case, the importing nation does not need to take any counter measure as a protection against dumping. Therefore, (no countermeasure, don't dump) is the Nash equilibrium. However, such scenario does not really exist in the real world of business, because the exporting nation can always find ways to keep its cost low due to different reasons, such as cheap labor or the availability of more advanced technology.

If $S_{\text {export }}>R_{0}$, it means that when the importing nation does not take any counter measure against dumping, the revenue of the exporting nation generated from dumping its product is greater than its risk and opportunity cost. In this case, it is evident that the exporting nation would most likely dump its product within the market of the importing nation. So, we have the payoffs of the two-player game given in Table 1.

Based on this setup, we derive the following implications. 1) For both nations, each unit of their product produced is successfully sold. 2) When the sales revenue of the exporting nation is greater than zero $\left(S_{\text {export }}>0\right)$, the sales revenue of 
Table 1 . The payoffs of the $2 \times 2$ pure strategy game.

\begin{tabular}{cccc}
\hline & \multicolumn{2}{c}{ Importing nation } \\
\cline { 2 - 4 } Exporting & \multicolumn{2}{c}{ Countermeasure } & No countermeasure \\
\cline { 2 - 4 } nation & Dump & $S_{\text {import }}-C-S_{\text {export }}, S_{\text {export }}-R_{1}$ & $S_{\text {import }}-S_{\text {export }}, S_{\text {export }}-R_{0}$ \\
& No dump & $S_{\text {import }}-C, 0$ & $S_{\text {import }}, 0$ \\
\hline
\end{tabular}

the importing nation is the net of the revenue of the like products sold in the importing nation and the portion of sales revenue the exporting nation takes away from the importing nation $\left(S_{\text {import }}-S_{\text {export }}\right.$ ), assuming that there is an increasing total sale of the exporting nation. 3 ) When the importing nation takes counter measures to prevent exporting nation from dumping its product, the total cost for the exporting nation to design and produce its product goes higher. That is, $R_{1}>R_{0}$. The rest of this paper assumes that all players establish their best responses by playing the Nash equilibrium through pure self-analyses.

Next, we analyze this game in three different cases, due to the fact that the decision of whether or not the exporting nation would dump its product depends not only on its expected revenue and related risk and opportunity cost but also on the decision of whether or not the importing nation would take counter measures. Assume that such countermeasures incur the actual cost of $C$.

Case 1: $S_{\text {export }}>R_{1}>R_{0}$. In this case, the revenue $S_{\text {export }}$ of the exporting nation is greater than its cost $R_{1}$, including that of risk and opportunity, when the importing nation takes counter measures. So, the exporting nation would evidently dump its product. On the other hand, because the exporting nation would surely dump its product regardless of whether or not there is antidumping measures, the importing nation would therefore not take any counter measures in order to decrease the severity of loss and save the potential cost $C$. As a result, dumping action by the exporting nation and no imposition of antidumping by the importing nation, (dump, no countermeasure), is the Nash equilibrium.

Case 2: $R_{0}<S_{\text {export }}<R_{1}$ and $S_{\text {export }}<C$. In this case, (Dump, No countermeasure) is the Nash equilibrium. In other words, when the importing nation takes counter measures against the potential dumping of the exporting nation, the importing nation has to spend more than its loss in terms of revenue. Consequently, due to the high costs, the importing nation would not take any counter measure; and the exporting nation would dump its product.

Case 3: $R_{0}<S_{\text {export }}<R_{1}$ and $S_{\text {export }}>C$. In this case, (No countermeasure, Dump) is the Nash equilibrium. However, since the importing nation would lose more in revenue $S_{\text {export }}$ than its risk and opportunity $\operatorname{cost} C$, the importing nation would take countermeasures if it moves first. Because the revenue $S_{\text {export }}$ of the exporting nation is smaller than the risk and opportunity cost $R_{1}$, there is no motivation for the exporting nation to dump its product. That is, in the subgame for the importing nation to take countermeasures, (No dump, Countermeasure) is the Nash equilibrium.

Based on what is discussed above using the theoretical game model, the results 
can be summarized as follows:

Theorem 1. For the various relationships between the revenue generated from dumping by the exporting nation and the cost associated with antidumping measures imposed by the importing nation described above, the following hold true:

1) If the expected profits generated from dumping is no more than the fixed cost of designing and producing the products, then the exporting nation would not produce and dump its product, while the importing nation does not need to do anything defensively;

2) If the expected profits generated from dumping by the exporting nation are less than the cost for the importing nation to take countermeasures, then the importing nation would not take any countermeasures against the dumping; and

3) If the expected profits from dumping by the exporting nation are more than the cost of taking countermeasures by the importing nation, then the importing nation would move first and take countermeasures against the dumping by the exporting nation.

\subsection{Mixed Strategies for the Game of Dumping and Antidumping}

Continuing the analysis of Case 3 above, to make the decision making process more dynamic, instead of using pure strategies, let us assume that the importing nation assigns probability $p$ for the event that it takes countermeasures. So, the payoff matrix of this $2 \times 2$ mixed strategy game can be described as in Table 2 .

For the exporting nation, its indifference condition is

$$
p\left(S_{\text {export }}-R_{1}\right)+(1-p)\left(S_{\text {export }}-R_{0}\right)=0,
$$

from which we have

$$
p=\frac{S_{\text {export }}-R_{0}}{R_{1}-R_{0}}
$$

This analysis leads to the following practically useful results:

Proposition 1. If all other conditions are held constant, then the variables $p$ and $S_{\text {export }}$ are directly proportional to each other.

The practical implication of this result is that the more the importing nation expects to lose its revenue, the higher the probability the importing nation would take countermeasures against the dumping of the exporting nation. On the other hand, the higher the probability the importing nation would take countermeasures, the more revenue the exporting nation is expected to earn from dumping its product in the importing nation.

\begin{tabular}{|c|c|c|c|}
\hline \multirow{4}{*}{$\begin{array}{c}\text { Exporting } \\
\text { nation }\end{array}$} & & \multicolumn{2}{|c|}{ Importing nation } \\
\hline & & Countermeasure $(p)$ & No countermeasure $(1-p)$ \\
\hline & Dump & $S_{\text {import }}-C-S_{\text {export }}, \quad S_{\text {export }}-R_{1}$ & $S_{\text {import }}-S_{\text {export }}, \quad S_{\text {export }}-R_{0}$ \\
\hline & No dump & $S_{\text {import }}-C, 0$ & $S_{\text {import }}, 0$ \\
\hline
\end{tabular}

Table 2. The payoffs of the $2 \times 2$ mixed strategy game. 
Proposition 2. If all other conditions are held constant, then the variables $p$ and $R_{1}$ are inversely proportional to each other.

In practice, Proposition 2 states that the higher the cost for the exporting nation to produce and dump its product, the smaller the probability for the importing nation to take countermeasures. On the other hand, the smaller the probability for the importing nation to take countermeasures, the higher the cost will be for the exporting nation to successfully produce and dump its product. The countermeasures the importing nation [13] could take might include ways to impose fines, increase tariffs, etc. So, the cost for the exporting nation to produce and dump its product will increase and the chance for the exporting nation to move ahead to produce and dump its product will decline. In the contrary, the lower degree for the importing nation to take countermeasures against dumping of the exporting nation, the lower level of costs will be for the exporting nation to produce and dump its product. Therefore, each initiative the importing nation takes as a contingent protection against dumping or to minimize the chance of potential dumping will be associated with increased costs for the exporting nation. In practice, the importing nation has to continuously improve its product in order to retain and even grow its domestic market. Other the other hand, if the importing nation does not implement strong countermeasures against dumping, then various products could more easily appear in the marketplace and will sooner or later push domestic firms out of competition. More specifically, when the probability for the importing nation to take countermeasures is $p=S_{B} / R_{1}$, where $R_{0}=0$ when countermeasures are taken, the exporting nation will have to consider its production and dumping of a different product. In such a case, the expected revenue of the importing nation will be maximized at $S_{\text {import }}-p C$.

Theorem 2. For the exporting and importing nations described above, if the importing nation makes dynamic decisions regarding whether or not to take countermeasures against the exporting-nation's dumping, then the more the importing nation expects to lose to the exporting nation up to the cost for the exporting nation to produce and dump its product, the more likely the importing nation will take countermeasures. And the more expensive for the exporting nation to produce and dump its product, the less likely the importing nation will take countermeasures.

\subsection{Dumping in the World Market}

In this subsection, let us consider the case that when deciding on producing and dumping its product, other than the possibility of taking a portion of the importing nation's revenue, the exporting nation also knows the fact that its product appeals to the customers of other nations from around the world. That is, the exporting nation could ultimately dump its product in the global market [16]. To this end, assume that the international market the product of the exporting nation will enter competitively is currently served by $m$ nations, $m=1,2, \cdots$. 
The customers of these nations are served with mutually substitutable products; and each of these nations enjoys the backing of its loyal customers who only purchase the product provided by their favorite nations if the price is no more than their reservation value, which is set to 1 . Assume that these nations compete over those customers who switch from the product of one nation to that of another nation when the prices are comparable and adjustable, that these nations are well aware of the pricing strategies of each other, and that these nations have established their best responses by playing the Nash equilibrium through pure self-analyses.

Speaking differently, the previous assumptions mean that the national market of each of the product-providing nations is in a state of mutual forbearance, where firms mitigate rivalry by dividing the market in proportion to firm strength [20]. They cede dominance to their stronger competitors in those market segments where they are less efficient, while in exchange the latter do the same in segments where the former are more efficient [21]. The firms' codependence gradually motivates them to de-escalate rivalry [22], making interfirm hostility decline [23]. That is, the incumbent firms of each national market can be seen theoretically as one large aggregate company that competes with other national aggregate companies in the world level.

The previous assumption about the $m$ product-providing nations generally means that the technology involved and the relevant business operations have been standardized. Therefore, for the particular exporting nation to enter and dump its product in such a market with profit potential, it is reasonable to assume that this exporting nation has come up with a more efficient technology and/or operation system (such as government subsidies) that can significantly reduce the overall business expenditure. For example, Christensen et al. [24] empirically investigate the linkage between technologies and their effect on firm's survival. Their finding suggests that technological and market strategies of a new entrant are highly interrelated and that their joint effect plays an important role in a firm's probability of survival.

For convenience of communication, assume that the marginal costs of the incumbent nations and the exporting nation are constant and set to zero without loss of generality. Furthermore, the aggregate of the incumbent nations is considered as one nation, because these $m$ nations are also in a state of mutual forbearance [20]. If the percentage share of this aggregate nation of the world market is $\alpha$, then $\beta=1-\alpha$ represents the market percentage of switchers who base their purchase decision on which price is lower. By incorporating all these assumptions, we have the following result.

Theorem 3. The exporting nation can profitably dump its product in the pre-described world market, as a competitor of the incumbent nations, if, and only if, the size of the market segment of switchers is greater than 0, i.e., $\beta=1-\alpha>0$, where $\alpha$ stands for the percentage of the market of the loyal customers of the $m$ nations. 
Proof. $(\Rightarrow)$ Suppose that the exporting nation dumps its product profitably into the oligopoly market of $m$ nations. Then, the percentage of the market switchers or customer surplus must satisfy $\beta=1-\alpha>0$.

$(\Leftrightarrow)$ Assume that the customer surplus satisfies $\beta=1-\alpha>0$. Firstly, let $\alpha_{0}$ be a real number so that $\beta=1-\alpha>\alpha_{0}>0$, and $\alpha=\ell \alpha_{0}$, where $\ell$ is a large natural number, indicating that the world market has been largely taken by the incumbent nations.

Secondly, imagine that the aggregate nation is divided into $\ell$ many identical "nations", named $i, i=1,2, \cdots, \ell$. Each of these nations provides the world market with identical products and enjoys the market share of $\alpha_{0}=\alpha / \ell$ of loyal customers. These imaginary nations compete over the switchers with adjustable prices. Due to the fact that these imaginary nations are really equal partitions of the same aggregate nation, they have the same constant marginal cost, which is set to zero without loss of generality. In addition, the decision makers of these nations are fully aware of the pricing strategies implemented by all the nations (because the nations are managed by the same administrative unit), and they establish their best, identical responses by playing the Nash equilibrium through their unified self-analyses.

Thirdly, these $\ell$ imaginary nations do not have any symmetric pure strategy Nash equilibrium. (For the setup here, there is no need to consider asymmetric pure strategy Nash equilibrium, because all these imaginary nations take identical actions). In fact, for any symmetric pure strategy portfolio $\left(x_{1}, x_{2}, \cdots, x_{\ell}\right)$, where $x_{i}=x_{j}$, for $i, j=1,2, \cdots, \ell$, a randomly chosen nation $j(\in\{1,2, \cdots, \ell\})$ can slightly lower its price from $x_{j}$ to $x_{j}^{\prime}$ to produce additional profits for all the nations as long as $x_{j}^{\prime} \beta>\left(x_{j}-x_{j}^{\prime}\right) \alpha$, which is possible to do by adjusting $x_{j}^{\prime}$ sufficiently close to $x_{j}$. Therefore, $\left(x_{1}, x_{2}, \cdots, x_{\ell}\right)$ is not an Nash equilibrium. Even so, Forrest et al. [25] show that these $\ell$ firms do have a symmetric mixed-strategy Nash equilibrium.

For the rest of this proof, it suffices to show that the exporting nation is expected to generate profit from dumping its product in the world market through uniformly randomizing its price strategy over the interval $[0,1]$.

Let $F(P)$ be the price distribution of Nation $j$, one of the imaginary nations of the aggregate nation. The aggregate nation or equivalently each of the $\ell$ imaginary forms sets its price after taking into account the price of the exporting nation and those of all other imaginary nations. Hence, the profits for Nation $j$ from its loyal customers is $\alpha_{0} P$ and those from its share of the switchers is $\prod_{i \neq j}^{\ell}(1-P)\left[1-F_{i}(P)\right] \beta P=\beta P(1-P)[1-F(P)]^{\ell-1}$, where $F_{i}(P)=F(P)$. As a result, the profits $\Pi$ Nation $j$ generates when the nation sells its product at price $P$ are

$$
\alpha_{0} P+\beta P(1-P)[1-F(P)]^{\ell-1}
$$

and the objective function of Nation $j$ is to maximize its expected profits by choosing its price distribution $F(P)$, which can be described as follows: 


$$
\begin{aligned}
\max _{F(P)} E\left(\Pi_{j}\right) & =\int_{-\infty}^{+\infty}\left\{\alpha_{0} P+\beta P(1-P)[1-F(P)]^{\ell-1}\right\} \mathrm{d} F(P) \\
& =\int_{0}^{1}\left\{\alpha_{0} P+\beta P(1-P)[1-F(P)]^{\ell-1}\right\} \mathrm{d} F(P)
\end{aligned}
$$

where $E\left(\Pi_{j}\right)$ stands for Nation $j$ s expected profits for all possible prices. The reason that the upper and lower limits of the integral are changed respectively from $+\infty$ and $-\infty$ to 1 and 0 is because when $P<0$ or when $P>1$, the profits are zero.

The equilibrium indifference condition of Nation $j$ is

$$
\alpha_{0} \times P+\beta \times P(1-P)[1-F(P)]^{\ell-1}=\alpha_{0} \times 1
$$

So, for the $\ell$ imaginary nations, solving Equation (1) will lead to their symmetric equilibrium pricing strategy, which is given as follows:

$$
F(P)=1-\left(\frac{\alpha_{0}}{\beta P}\right)^{\frac{1}{\ell-1}}
$$

From $\beta>\alpha_{0}$, it follows that $\alpha_{0} / \beta<1$. So, for any price $P$, satisfying $1 \geq P \geq \alpha_{0} / \beta$, Equation (2) is then a well-defined probability distribution. This implies that for the $\ell$ imaginary nations, or equivalently, the aggregate nation, the lowest allowed price is $\alpha_{0} / \beta$.

To complete this proof, it suffices to show that the exporting nation actually expects to make profits in the world market. To this end, as $\lim _{P \rightarrow 1^{-}} F(P)=1-\left(\alpha_{0} / \beta\right)^{1 /(\ell-1)} \neq F(1)=1$, the cumulative price distribution function $F(P)$ has a jump discontinuity at the reservation value of $P=1$, where the amount of jump is $\left(\alpha_{0} / \beta\right)^{1 /(\ell-1)}$. That is, $F(P)$ has a mass point of size $\left(\alpha_{0} / \beta\right)^{1 /(\ell-1)}$ at the reservation price of $P=1$. Therefore, the expected profits of the exporting nation are given as follows:

$$
\begin{gathered}
E(\Pi)=\int_{0}^{\alpha_{0} / \beta} \beta P \mathrm{~d} P+\int_{\alpha_{0} / \beta}^{+\infty} \beta P[1-F(P)]^{\ell} \mathrm{d} P \\
=\int_{0}^{\alpha_{0} / \beta} \beta P \mathrm{~d} P+\int_{\alpha_{0} / \beta}^{1} \beta P[1-F(P)]^{\ell} \mathrm{d} P+\beta\left(\frac{\alpha_{0}}{\beta}\right)^{\ell /(\ell-1)}
\end{gathered}
$$

where the first term in the right-hand side of Equation (3a) stands for the expected profits of the exporting nation when it charges the lowest price in the marketplace and captures the entire segment of the switchers, and the second term is the exporting-nation's expected profits when it is in direct competition with the $\ell$ incumbent nations.

Because the first term in the right-hand side of Equation (3b) satisfies

$$
\int_{0}^{\alpha_{0} / \beta} \beta P \mathrm{~d} P=\frac{\alpha_{0}^{2}}{2 \beta}>0,
$$

the second term is $\geq 0$, because the integrant is positive and the third term is positive, it can be concluded that the expected profits $E(\Pi)$ of the exporting nation is greater than zero. These conditions imply that if the customer surplus 
satisfies $\beta=1-\alpha>0$, the exporting nation can profitably dump its product in the world market to compete with the incumbent product-providing nations. QED

Specifically, what Theorem 3 implies is that the exporting nation expects to profit by taking first a portion of the profits of the particular importing nation and then a portion of the greater world market of its product. In other words, it is practically possible that the additional profits the exporting nation expects to generate from dumping its product in the world market will be more than $S_{\text {export }}$, the sales revenue of the exporting nation from the importing nation by producing and dumping its product in the importing nation. Let $S_{\text {export }}$ represent the revenue the exporting nation generates from the world market excluding the particular importing nation, as described in Theorem 3. Then, we naturally have the following possibility:

$$
S_{\text {export }}+S_{\text {export }} \geq \max \left\{R_{1}, C\right\} .
$$

That is, the expanded sales revenue of the exporting nation from producing and dumping its product is at least the larger of the nation's cost $\left(R_{1}\right)$ of producing and dumping its product and the cost $(C)$ of the importing nation for it to take countermeasures against dumping. In this case, (Dump, No countermeasure) is the pure strategy Nash equilibrium with the corresponding payoffs $\left(S_{\text {export }}-R_{0}, S_{\text {import }}-S_{\text {export }}\right)$, as shown in Table 1 . In other words, the market share of the incumbent firms in the importing nation erodes and is gradually taken by the exporting-nation's product while the importing nation cannot do anything about it. That is, the domestic manufacturer of the particular product of the importing nation will soon be chased out of its existence unless it switches its production to a different product. Summarizing what is discussed here, we have.

Corollary 1. If the exporting-nation's dumping is expected to generate profits from other nations beyond the particular importing nation, then the exporting nation will produce and dump its product worldwide. Such action will prevent the domestic producers of the product in the particular importing nation from surviving and ultimately force them to exit their specific market.

\section{Consumers: The Ultimate Determining Factor of the Market}

In the previous discussions, the role of consumers, particularly those of the importing nation, was not considered. To this end, let us consider one customer of the importing nation, who decides to buy or not to buy the product of concern.

Assume that the exporting nation could observe the actions undertaken by the importing nation, while neither the importing nation nor the customer could predict or observe whether or not the exporting nation is dumping its product. Evidently, taking countermeasure against dumping is a clear strategic choice of actions the importing nation could select in order to at least in theory protect its domestic market and consumers. 
To analyze the competition, assume that the importing nation will incur a cost of $C$ if it chooses to take countermeasures against dumping, and 0 if no countermeasure is undertaken. After observing the policy decision of the importing nation, the exporting nation has two choices of action to consider: dump or don't dump its product with the associated fixed costs of $D$ if dump or 0 otherwise. When facing a choice between domestically-made product and dumped product, it is rational to assume that the customer will prefer to buy the dumped product due to various reasons, such as competitive price and none distinguishability between the two products, if such product is available in the domestic market. His or her utility is $(-u)$ if he or she buys dumped product due to various related issues, such as inferior quality, dissatisfactory service, etc., is $u$ if he or she buys domestically-made product, and is 0 if he or she decides not to make any purchase, in which case the revenue for both nations is 0 . As before, let $S_{\text {export }}$ be the revenue of the exporting nation generated from dumping its product in the importing nation, $S_{\text {import }}$ the revenue of the importing nation generated from its domestic market when the exporting nation does not dump its product, and $S_{\text {export }}{ }^{-}$the revenue the exporting nation generates from dumping its product in the world market excluding the particular importing nation. Then we have $S_{\text {import }}>S_{\text {export }}$. When the importing nation takes countermeasures, the additional cost for the exporting nation is $\alpha C$, where $0<\alpha<1$. This is due to the fact that to follow up with the importing-nation's countermeasures, the exporting nation has to push its organization's knowledge envelope outward in order to incorporate unknown technologies in its effort to produce and dump its product effectively [26].

The payoffs of the exporting nation and the customer are respectively given in Table 3 for the case when the importing nation takes countermeasures and in Table 4 for the case when the importing nation does not take any countermeasures.

Proposition 3. If $S_{\text {export }}+S_{\text {export }}<D+\alpha C$, then (No dump, No countermeasure, Don't buy) is the pure strategy Nash equilibrium with the corresponding payoffs $(0,0,0)$. That is, it is strategically beneficial for the exporting nation not to dump its product, while the importing nation has no reasons to impose any countermeasure and the customer does not have a desire to make a purchase.

This result follows from the payoffs of the importing nation that are corresponding to the scenarios that this nation either takes countermeasures or does not (either Table 3 or Table 4). For details see Table 5 and Table 6, respectively.

This result implies that when the additional revenue the exporting nation expects to generate from its product is less than the total cost of producing and dumping its product, then the exporting nation would not produce and dump its product. Consequently, the importing nation does not need to take any countermeasures; and if the customer of the importing nation decides to purchase, she has no choice but purchase the product available on the market. 
Table 3. Payoffs when the importing nation takes countermeasures

\begin{tabular}{lccc}
\hline & \multicolumn{2}{c}{ Customer } \\
\cline { 2 - 3 } Exporting & \multicolumn{2}{c}{$\operatorname{Buy}(\tau)$} & Don't buy $(1-\tau)$ \\
\cline { 2 - 3 } nation & $\operatorname{Dump}(p)$ & {$\left[\left(S_{\text {export }}+S_{\text {export }}\right)-D-\alpha C\right], u$} & {$\left[\left(S_{\text {export }}\right)-D-\alpha C\right], 0$} \\
& No dump $(1-p)$ & $0,-u$ & 0,0 \\
\hline
\end{tabular}

Table 4. Payoffs when the importing nation does not take any countermeasures.

\begin{tabular}{|c|c|c|c|}
\hline \multirow{3}{*}{$\begin{array}{c}\text { Exporting } \\
\text { nation }\end{array}$} & & \multicolumn{2}{|c|}{ Customer } \\
\hline & & Buy $(\varepsilon)$ & Don't buy $(1-\varepsilon)$ \\
\hline & $\operatorname{Dump}(q)$ & $\left.\left(S_{\text {export }}+S_{\text {export }}\right)-D\right], u$ & {$\left[\left(S_{\text {export }}\right)-D\right], 0$} \\
\hline & No dump $(1-q)$ & $0,-u$ & 0,0 \\
\hline
\end{tabular}

Table 5. The payoffs of the importing nation and the customer when the former takes countermeasures.

\begin{tabular}{cccc}
\hline & & \multicolumn{2}{c}{ Customer } \\
\cline { 3 - 4 } Exporting & & Buy $(\tau)$ & Don't buy $(1-\tau)$ \\
\cline { 2 - 4 } nation & Dump $(p)$ & $-C$ & $-C$ \\
& No dump $(1-p)$ & $S_{\text {import }}-C$ & $-C$ \\
\hline
\end{tabular}

Table 6. The payoffs of importing nation and the customer when the former does not take any countermeasures.

\begin{tabular}{|c|c|c|c|}
\hline \multirow{3}{*}{$\begin{array}{c}\text { Exporting } \\
\text { nation }\end{array}$} & & \multicolumn{2}{|c|}{ Customer } \\
\hline & & Buy $(\varepsilon)$ & Don't buy $(1-\varepsilon)$ \\
\hline & Dump (q) & 0 & 0 \\
\hline & No dump $(1-q)$ & $S_{\text {import }}$ & 0 \\
\hline
\end{tabular}

Proposition 4. If $S_{\text {export }}+S_{\text {export }}>D+\alpha C$, then (Dump, No countermeasure, Buy), the pure strategy Nash equilibrium, will provide payoffs of $\left(\left(S_{\text {export }}+S_{\text {export }}\right)-D, 0, u\right)$. That is, it is beneficial for the exporting nation to dump its product, while the importing nation does not take any antidumping scheme and the customer buys the dumped product.

This result implies that when the additional revenue the exporting nation expects to generate from its product is more than the total cost of producing and dumping the product, then this nation will move ahead with its production and dumping of the product, while the importing nation does not even attempt to take any countermeasures.

Next, let us consider the case where $S_{\text {export }}+S_{\text {export }}>D+\alpha C$ and $S_{\text {export }}<D+\alpha C$. That is, the total revenue the exporting nation expects to generate from producing and dumping its product is greater than the relevant cost, while the revenue from the rest of the world is less than this cost. The second 
condition is constrained because the exporting nation will most certainly produce and dump its product in the world market when $S_{\text {export }^{-}} \geq D+\alpha C$.

We further assume that when the importing nation takes countermeasures, the probability for the exporting nation to produce and dump its product is $p$, and the probability for the customer to purchase is $\tau$. According to [27], before the exporting nation commits to any decision, it has to first collect information regarding the situation, and then seize the opportunity to reposition itself by acquiring the necessary capabilities for successful organizational adaptation. On the other hand, when the importing nation does not take any countermeasures, the probability for the exporting nation to produce and dump its product is $q$, and the probability for the customer to purchase $\varepsilon$. For details see Tables 3-6. To examine this theoretical game, we solve following indifference equations for mixed strategy Nash equilibrium:

$$
\begin{gathered}
p u+(1-p)(-u)=0 \\
q u+(1-q)(-u)=0 \\
\tau\left[\left(S_{\text {export }}+S_{\text {export }}\right)-D-\alpha C\right]+(1-\tau)\left[\left(S_{\text {export }^{-}}\right)-D-\alpha C\right]=0 \\
\varepsilon\left[\left(S_{\text {export }}+S_{\text {export }^{-}}\right)-D\right]+(1-\varepsilon)\left[\left(S_{\text {export }}\right)-D\right]=0
\end{gathered}
$$

which provides $p=q=1 / 2$ and

$$
\tau=\frac{D+\alpha C-S_{\text {export }^{-}}}{S_{\text {export }}}, \varepsilon=\frac{D-S_{\text {export }}}{S_{\text {export }}}
$$

which lead to the following conclusions:

Proposition 5. If $S_{\text {export }}+S_{\text {export }}>D+\alpha C$ and $S_{\text {export }}-<D+\alpha C$ hold true and all other conditions are held constant, then

1) The more the importing nation spends on countermeasures, the more likely the customer will buy the dumped product from the exporting nation; and

2) Regardless of whether or not the importing nation takes any countermeasures, the more revenue the imported product makes within the importing nation, the less likely the customer will buy the dumped products.

In fact, under the condition of conclusion 1, the increased strength of countermeasures of the importing nation makes it difficult for the exporting nation to dump its product in the particular importing nation so that the availability of the imported product becomes less in the domestic market of the nation. The scarcity makes the customer more willing to try the dumped product. However, this increasing probability of purchase does not mean that the revenue of the exporting nation from dumping its product in this particular importing nation will go up. In other words, without taking more revenue away from the importing nation, the chance for the importing nation to continuously spend additional amounts on countermeasures will be less. This is due to the fact that further spending on countermeasures will not create much or any tangible benefits.

Under the condition of conclusion 2, the rising revenue of the exporting na- 
tion generated through dumping its product in the importing nation is a result of the wide availability of the dumped product in the importing nation. The associated issues related to the foreign dumped product include quality, follow-up service, etc., which become more rampant and ultimately lead to lowering probability for the customer to buy. In other words, the more the dumped product is available, the less likely the customer will buy. This inverse relationship between the supply of the dumped product and customers' willingness to purchase confirms rigorously what is reported by Huntington [28] and explained by Lin and Forrest [12]: The more a nation imports goods from a particular nation, the more antagonistic the citizens of the receiving nation become towards the exporting nation.

\section{Cost-Benefit Analysis}

Assume that $S_{\text {export }}+S_{\text {export }}>D+\alpha C$ and $S_{\text {export }}<D+\alpha C$. In this case, any antidumping enforcement of the importing nation would generate a threat on the revenue of the exporting nation [18]. Hence, the expected revenue of the importing nation is given by

$$
\begin{aligned}
\pi_{\text {import,countermeasure }}= & p \tau\left(S_{\text {import }}-C-S_{\text {export }}\right)+p(1-\tau)(-C) \\
& +(1-p) \tau\left(S_{\text {import }}-C\right)+(1-p)(1-\tau)(-C)
\end{aligned}
$$

if the importing nation takes any countermeasures; and

$$
\pi_{\text {import }, \text { no countermeasure }}=q \varepsilon\left(S_{\text {import }}-S_{\text {export }}\right)+(1-q) \varepsilon S_{\text {import }}
$$

if the importing nation does not take any countermeasures. Substituting $p=q=1 / 2, \tau$ - and $\varepsilon$-values in Equation (4) into Equations (5) and (6) produces the following:

$$
\pi_{\text {import, countermeasure }}=\frac{S_{\text {import }}\left(D+\alpha C-S_{\text {export }}\right)}{S_{\text {export }}}-\frac{1}{2}\left(D+\alpha C-S_{\text {export }}\right)-C
$$

and

$$
\pi_{\text {import }, \text { no countermeasure }}=\frac{1}{2} \frac{D-S_{\text {export }}}{S_{\text {export }}}\left(2 S_{\text {import }}-S_{\text {export }}\right) .
$$

Differentiating Equation (7) with respect to $C$ leads to

$$
\frac{\partial\left(\pi_{\text {import, countermeasure }}\right)}{\partial C}=\frac{\alpha S_{\text {import }}}{S_{\text {export }}}-\frac{\alpha}{2}-1=\alpha\left(\frac{S_{\text {import }}}{S_{\text {export }}}-\frac{1}{2}\right)-1,
$$

which implies that when $S_{\text {import }}<\left(\frac{1}{\alpha}+\frac{1}{2}\right) S_{\text {export }}, \pi_{\text {import,countermeasure }}$ is a decreasing function of $C$. In other words, as soon as the product of $(1 / \alpha+1 / 2)$ and the revenue the exporting nation generates from the importing nation's market is greater than the importing nation's ideal revenue when it does not experience any dumping from the exporting nation, then the importing nation can no longer prevent the exporting nation to dump its product by continuously in- 
creasing its investment in countermeasures. In particular, when $\alpha=0.25$ and $S_{\text {export }}>2 S_{\text {import }} / 9$, the importing nation has to do more than simply taking countermeasures to stop the exporting nation from dumping its product.

On the other hand, if the importing nation's maximum revenue $S_{\text {import }}$ is greater than $\left(\frac{1}{\alpha}+\frac{1}{2}\right)$ times the revenue $S_{\text {export }}$ of the exporting nation, then the expected revenue $\pi_{\text {import,countermeasure }}$ of the importing nation is an increasing function of its cost of taking countermeasures. In this case, the more the importing nation spends on countermeasures, the more revenue it expects to generate.

If the importing nation does not take any countermeasure, Equation (8) implies that the expected revenue $\pi_{\text {import,no countermeasure }}$ of the importing nation will always be positive, because the condition $S_{\text {export }^{-}}<D+\alpha C$ means $S_{\text {export }^{-}}<D$, since $C=0$.

Summarizing what has been discussed in this section, we have the following result:

Theorem 4. If $S_{B}+S_{B^{-}}>D+\alpha C$ and $S_{B^{-}}<D+\alpha C$, then the following hold true:

1) If the importing nation decides to take countermeasures against dumping, then it can successfully defend its market as long as its maximum expected revenue is greater than $\left(\frac{1}{\alpha}+\frac{1}{2}\right)$ times the expected revenue taken by the exporting nation; and

2) If the importing nation decides not to take any countermeasures, then it can expect to make positive revenues, as given in Equation (8). However, this positive revenue decreases with increasing revenue the exporting nation generates from the rest of the world.

\section{A Case Study}

In the recent decades, with the increasing magnitude of activity of its international trades, China's import-export surplus has been swelling, especially the surplus with the United States of America. As a consequence, the issue of how to balance international trades has attracted more and more attention among academicians, practitioners, and policymakers. Balancing international trades appears to be an ongoing issue, evidenced by constant occurrence of trade conflicts among countries, including numerous antidumping mechanisms imposed by many countries against China's trades. During the past two years, for example, the United States has replaced India in becoming the nation of the world that has employed most antidumping and other trade remedy measures. China and, in particular, its steel industry have been the main target of United States' trade remedy measures. The United States has also imposed higher tariffs on Chinese imports as an antidumping countermeasure. Many Chinese industries, such as aluminum, steel, solar products, etc., have been listed by the United States as dumping industries. On May 17, 2016, the U.S. Department of Commerce [29] 
censured that various kinds of steels exported from China had received 256\% government's subsidies and decided to increase the antidumping duty rate on China's cold rolled steel to $522 \%$. Such antidumping mechanisms have greatly increased the price of Chinese products introduced in American market. Relevant study [30] also provides the support that antidumping duty rate could affect the production capacity and financial conditions of the exporter.

According to the World Trade Report [31], in 2015 alone the United States launched 43 cases of antidumping and 22 cases of countervailing investigations against China. From the number of the antidumping and countervailing cases, the United States has surpassed India, the nation that used most such measures in 2014, and Brazil, which employed most such measures in 2013. On the other hand, the European Union only launched 12 antidumping investigations, which were two cases fewer than in 2014. This report maintains that the United States' drastically increasing number of cases is mainly due to the steel industry. Speaking globally, there were a total of 46 metal-relevant antidumping cases among all 233 antidumping cases worldwide with metal-related cases being the majority. At the same time, it is easier for the United States to launch antidumping investigations than the European Union, because the latter has to first conduct a public interest review. However, the report points to the fact that the United States is more audacious than the European Union in its protection of the domestic steel industry. According to this report, in the past 20 years, India launched the most antidumping investigations with 767 cases, $15 \%$ of the global total, while the United States had 570 cases and the European Union 480 cases.

In support of this relevant fact, we conduct the case study between China as the exporter and the United States the importer, as so labelled in the earlier sections. By specifying the general terms developed in the game-theoretic models of the previous sections, we are able to derive following conclusions and managerial implications that can serve as practical guidelines for the policy makers of China and the U.S. involved in international trades. In particular, what is specified is that China is treated as the exporting nation that dumps one product in the U.S., as the importer, and the world market.

1) If China's expected revenue of dumping in the world market is no more than its fixed cost, then China would not produce and dump its product, while no nation needs to take countermeasures against China.

2) If China expects to generate more profits from dumping in the U.S. than the cost for the U.S. to take remedy measures, then the U.S. would take remedy measures against China's dumping.

3) The more China expects to lose its dumping revenue, the higher the probability the U.S. would take remedy measures. And, the higher the probability the U.S. would take remedy measures, the more the revenue China expects to earn from dumping in the U.S.

4) If the cost for China to produce a particular product is high, then the probability for the U.S. to take remedy measures against China's dumping of the product is low. 
5) Assume that the U.S. makes dynamic decisions regarding whether or not to take remedy measures against China's dumping. Then the more China expects to lose (up to its cost to produce and dump its product), the more likely the U.S. will take remedy measures.

6) Other than the U.S. market, China could also collect revenue from the rest of the world. And if China's profits from dumping its product in the world market are greater than the cost for the U.S. to take remedy measures, then China will dump its product and the U.S. will not take any defensive actions. That is, the U.S. domestic manufacturing of the particular product China dumps will soon disappear.

Assume that China's revenue from dumping in the world market except the U.S. is less than its cost of production and dumping in the entire world market, while the total revenue is greater than the cost. In other words, the U.S. market is vital for the Chinese product. Then, we have the following results:

7) If the U.S. takes remedy measures, then the more it spends on the measures, the more likely the U.S. customers will buy the Chinese product. On the other hand, regardless of remedy measures imposed by the U.S., the more revenue the Chinese product makes in the U.S., the less likely the U.S. customers will buy the Chinese product.

8) If the U.S. decides to defend itself against dumping, it can be successful, if its maximum expected revenue is sufficiently large compared to how much China expects to take away from the U.S.

9) If the U.S. decides not to defend itself against dumping, then its expected positive revenue will decrease with the revenue China generates from the rest of the world.

Contrast to what is obtained above, [32] comprehensively analyzes the European Union antidumping measures against Chinese imports. They investigate the effect of antidumping schemes on the performance of Chinese exporters, European producers, and European importers. Their findings suggest that although European Union antidumping measures successfully reduced the number of Chinese exporters, they result in an increasing productivity of those remaining, while the same antidumping measures have a mixed impact on the performance of European firms.

\section{Final Words}

Through rigorously modeling the interaction between an importer and an exporter, this paper develops a general theory on when trade dumping by the exporter could occur and when antidumping measures should be implemented by the importer and would yield positive effects. By placing our theory in the context of the world economy, what is established in this paper is made both theoretically valuable and practically significant. By taking a neutral stand, from neither the angle of the importer nor that of the exporter alone, we are able to find conditions under which the exporter could potentially dump its products prof- 
itably and when the importer should beneficially take defensive measures in order to protect its domestic market.

Other than enriching the literature on the age old problem of dumping/antidumping in international trade, the biggest contribution this paper makes is to illustrate how relatively local problems, involving mostly only two trading partners, could be beautifully seen worldly within the ever increasing economic globalization.

Due to how particular conditions are framed within this paper, it is expected that all of our established results can be readily employed as guidelines for policy decision makers, and can be easily utilized to analyze actual trading behaviors between any two given nations. That end is well validated by the case study on China-U.S. trade relationship given above. In particular, when looking at two trading partner nations in the roles of exporter $\mathrm{X}$ and importer $\mathrm{Y}$, a policy decision maker from either nation $\mathrm{X}$ or nation $\mathrm{Y}$ can apply what is established in this paper to her corresponding scenarios of decision making. For example, conclusion 4) in the previous section regarding the trade relationship between China and the U.S. in this case becomes: If the cost for $\mathrm{X}$ to produce a particular product is high, then the probability for $\mathrm{Y}$ to take remedy measures against $\mathrm{X}$ 's dumping of the product is low. In other words, to provide practical guidelines, all one needs to do is to respectively replace specific nations' roles as an exporter and an importer into the derived theoretical conclusions throughout the paper.

\section{Acknowledgements}

This work is partially funded by a Social Science Major Foundation of China (16ZDA014) and Social Science Foundation of Jiangxi Province (15YJ15). These sponsors were not in any way involved directly or indirectly in any step of this particular work.

\section{Conflicts of Interest}

The authors declare no conflicts of interest regarding the publication of this paper.

\section{References}

[1] Ricardo, D. (1817) On the Principles of Political Economy and Taxation. John Murray, London.

[2] Kao, K.F. and Peng, C.H. (2016) Anti-Dumping Protection, Price Undertaking and Product Innovation. International Review of Economics \& Finance, 41, 53-64. https://doi.org/10.1016/j.iref.2015.09.006

[3] Oliveira, G.A.S. (2014) Industrial Determinants of Anti-Dumping in Brazil-Protection, Competition and Performance: An Analysis with Binary Dependent Variable and Panel Data. Economia, 15, 206-227. https://doi.org/10.1016/j.econ.2014.07.003

[4] Satapathy, C. (2005) Trends in Anti-Dumping: First Decade of WTO. Working Paper http://www.esocialsciences.org/Download/repecDownload.aspx

[5] Rieber, W.J. (2016) Ludwig Von Mises’ Neoclassical Analysis of Dumping. Atlantic 
Economic Journal, 44, 447-455. https://doi.org/10.1007/s11293-016-9513-7

[6] Cantono, S. and Marchionatti, R. (2012) Dumping as Price Discrimination: Jannaccone's Classic Theory before Viner. Journal of the History of Economic Thought, 34, 193-218. https://doi.org/10.1017/S1053837212000168

[7] Robinson, J. (1933) The Economics of Imperfect Competition. Macmillan, London.

[8] Yntema, T.O. (1928) The Influence of Dumping on Monopoly Price. Journal of Political Economy, 36, 686-698. https://doi.org/10.1086/253986

[9] Viner, J. (1922) The Prevalence of Dumping in International Trade: I. Journal of Political Economy, 30, 655-680. https://doi.org/10.1086/253466

[10] Viner, J. (1923) Dumping: A Problem in International trade. University of Chicago Press, Chicago.

[11] Kerr, W.A. (2001) Dumping-One of Those Economic Myths. The Estey Centre Journal of International Law and Trade Policy, 2, 211-220.

[12] Lin, Y. and Forrest, B. (2011) Systemic Structure behind Human Organizations: From Civilizations to Individuals. Springer, New York.

[13] Dinlersoz, E. and Dogan, C. (2010) Tariffs versus Anti-Dumping Duties. International Review of Economics \& Finance, 19, 436-451. https://doi.org/10.1016/j.iref.2009.10.007

[14] Hansen, J. D., Meinen, P., and Nielsen, J. U. M. (2014) Elasticity of substitution and anti-dumping decisions. Review of World Economics, 150, 787 - 816. https://doi.org/10.1007/s10290-014-0198-1

[15] Haaland, J.I. and Ian Wooton, I. (1998) Antidumping Jumping: Reciprocal Antidumping and Industrial Location. Weltwirtschaftliches Archiv, 134, 340-362. https://doi.org/10.1007/BF02708100

[16] Moraga-González, J.L. and Viaene, J.M. (2005) Dumping in a Global World: Why Product Quality Matters. The World Economy, 28, 669-682. https://doi.org/10.1111/j.1467-9701.2005.00699.x

[17] Chen, Y.M., Liu, H.H. and Wu, H.Y. (2016) Reputation for Toughness and Anti-Dumping Rebuttals: Competitive Rivalry, Perceived Benefits, and Stage of the Product Life Cycle. Journal of Business Research, 69, 2145-2150. https://doi.org/10.1016/j.jbusres.2015.12.022

[18] Bagchi, S., Bhattacharyya, S. and Narayanan, K. (2014) Does Anti-Dumping Enforcement Generate Threat? Foreign Trade Review, 49, 31-44.

https://doi.org/10.1177/0015732513515988

[19] WTO (1994).

https://www.wto.org/english/res_e/booksp_e/analytic_index_e/anti_dumping_01_e. htm\#article2

[20] Bernheim, B.D. and Whinston, M.D. (1990) Multimarket Contact and Collusive Behavior. RAND Journal of Economics, 21, 1-26. https://doi.org/10.2307/2555490

[21] Li, S.X. and Greenwood, R. (2004) The Effect of Within Industry Diversification on Firm Performance: Synergy Creation, Multi-Market Contact and Market Structuration. Strategic Management Journal, 25, 1131-1153. https://doi.org/10.1002/smj.418

[22] Yu, T. and Cannella, A.A. (2012) A Comprehensive Review of Multimarket Competition Research. Journal of Management, 39, 76-109.

https://doi.org/10.1177/0149206312462456

[23] Haveman, H.A. and Nonnemaker, L. (2000) Competition in Multiple Geographic Markets: The Impact on Growth and Market Entry. Administrative Science Quarterly, 45, 232-267. https://doi.org/10.2307/2667071 
[24] Christensen, C.M., Suárez, F.F. and Utterback, J.M. (1998) Strategies for Survival in Fast-Changing Industries. Management Science, 44, S207-S220. https://doi.org/10.1287/mnsc.44.12.S207

[25] Forrest, Y.L.J., Buttermore, J. and Wajda, T.A. (2017) At Nash Equilibrium When New Market Competitions Appear? Kybernetes: The International of Cybernetics, Systems and Management Science, 46, 256-271.

[26] Harrigan, K.R. and DiGuardo, M.C. (2016) Sustainability of Patent-Based Competitive Advantage in the U.S. Communications Services Industry. The Journal of Technology Transfer, 42, 1334-1361.

[27] Day, G.S. and Schoemaker, P.J.H. (2016) Adapting to Fast-Changing Markets and Technologies. California Management Review, 58, 59-77.

https://doi.org/10.1525/cmr.2016.58.4.59

[28] Huntington, S.P. (1996) The Clash of Civilizations and the Remaking of World Order. Simon \& Schuster, New York.

[29] U.S. Department of Commerce (2016). https://agmetalminer.com/2016/05/19/are-manufacturers-and-consumers-hurt-by-s teels-anti-dumpingcvd-lawsuits/

[30] Liu, C.S., Hsiao, C.T., Chang, D.S. and Hsiao, C.H. (2016) How the European Union's and the United States' Anti-Dumping Duties Affect Taiwan's PV Industry: A Policy Simulation. Renewable and Sustainable Energy Reviews, 53, 296-305. https://doi.org/10.1016/j.rser.2015.08.036

[31] WTO (2016) World Trade Report. https://www.wto.org/english/res_e/booksp_e/world_trade_report16_e.pdf

[32] Jabbour, L., Vanino, E., Tao, Z.G. and Zhang, Y. (2016) The Good, the Bad and the Ugly: Chinese Imports, EU Anti-Dumping Measures and Firm Performance. Research Paper Series, Research Paper 2016/16, The University of Nottingham, Nottingham. 